\title{
Appearances of Motivation According to Branch of Study of Students to Public Universities in Albania
}

\author{
Arben Hoti \\ Phd. Candidate, University of Shkodra "Luigj Gurakuqi", Faculty of Education, Departmant of Psychology -Social Work, Albania \\ Email: benhoti@yahoo.com
}

\author{
Doi:10.5901/ajis.2015.v4n2s2p295
}

\section{Abstract}

\begin{abstract}
The performance of a student is inevitably influenced by motivation. It can be external or internal, medium, low or high. As the studies in different countries show, motivational level is also associated with the field of study that students have chosen to follow. Furthermore they express the kind of motivation according to the selected field of study. The connection that exists between the student and field of studies, the relationship he/she establishes with, the ways of expression about its requirements, performance and continuity of achievement and success in his/her field of study, etc. constitute some of the students' motivational resources. This article brings a demonstration of this approach in the Albanian reality showing us data derived from empirical and research work realised in Albanian universities. With the extract from a research during several years in the framework of a doctoral dissertation in the field of psychology, the paper aims to present the role that has the selected field of study in the level of motivation at the students involved champion. The focus of this paper are students of public Albanian universities such as, Tirana University, "Aleksander Moisiu" University in Durres and the University "Luigi Gurakuqi" in Shkodra. To have a pretense of study fields as well as the social and scientific direction, the selected fields are: Psychology, Social Work, Economics and History, in each of the aforementioned universities. The data derived through the use and processing of data using scientific research programs and special facts will show us about fields of study that Albanian students have chosen, their level of motivation, what is the motivation of their connection with the field of study, the impact that social or scientific orientation has in student motivation part of our champion, etc.
\end{abstract}

Keywords: motivation, external motivation, internal motivation, academic performance

\section{Introduction}

This article brings a research paper within the doctoral program in the field of research in Psychology. It is related to student motivation. Rather the doctoral thesis is expressed displaying student motivation Albanian public universities, connection type with the branch of study motivation, motivation link on student academic achievement, gender differences in terms of motivation, etc.

All these are related and presented with the hypothesis of the paper in question. Here in this article we present specific performances at student motivation in Albanian public universities. It also constitutes the main purpose of the article. As these performances are related with the motivation of the study branches based on the average grade (GPA) students selected as champion.

The focus of this research work are students of Albanian public universities, University of Tirana, University "Aleksander Moisiu" in Durres and the University "Luigi Gurakuqi" in Shkodra.

\section{Theoretical treatment}

Issues of motivation are important parts of research and study in the field of psychology and especially in motivational psychology.

The term motivation summarizes internal forces put into operation individual governing certain activities and facility to regulate this activity. The motivation includes the whole system of regulation of the activity at individual motives including conscious and unconscious.

Motives are organic factors, environmental (social) and psychological who set in motion or guide human activity, as his behavior and also perception, learning, thinking, etc (Sahar Mahmoud Radi 2013).

For researchers in the field of psychology, motivation is defined as the rate on the basis of which a person wants and chooses his involvement in a certain behavior. Motivation can be oriented externally or internally (Afzal ed al 2010). 
Internal motivation is defined as motivation to engage in an activity for its own sake, while external motivation refers to motivation to engage in an activity as a means to put something in the end (Sansone and Harackiewicz, 2000).

As well as internal and external motivation have elements of their referees have different so we can mention the internal and external motivation element such as motivation: careers and qualifications altruism, self-exploration, social satisfaction, the refusal of alternative options, social pressures, ect.

Oriented motivational forms in student learning may reflect their need for personal fulfillment or environmental (Boshier, 1991; Abdul Razaq Ahmad et al, 2009). students with internal motivation are more enthusiastic, self-directed, challenging and delight in their studies, they also tend to use strategies that require more effort and allows them to process the information more intensively (Pintrich and SCHUNK, 2002), while foreign students motivation try to drag yourself with academic tasks, feel forced to learn, and always make minimal effort to achieve maximum ratings (Hindi and Harackiewicz, 2000).

There are many studies that address the role, influence and motivation links with the learning process, success and academic achievements of university students.

Some of them, that we have used our instrument TUSMQ-2, such as: "Baccalaureate Nursing Students' Motivation for Attending University and its Relationship with their Academic Achievement" by Sahar Mahmoud Radi; "A Study of University Students' Motivation and Its Relationship with Their Academic Performance" by Hasan Afzal et al; "The influence of motivational orientations on academic achievemnt among working adults in contiuing education" by Pei-Ling Lee \& Vincent Pang; "Motivational orientations in adult learning: comparing a public and private university" by Pei-Ling Lee and Vincent Pang; "Motivational Factors in Continuing Education and Academic" by Pei Ling Lee \& Vincent Pang (Pei-Ling Lee and Vincent Pang 2013).

Studies show a significant positive relation between motivation of the student and his academic performance. This relationship is reciprocal, which means that students who are motivated have better performance and students have better performance become more motivated (Afzal et al., 2010).

Another study that is projected to determine the expectations of students' academic performance of athletes at the University of Oklahoma's. The findings of this study concluded that given academic motivation was significant predictor of academic performance. (Gaston-Gayles, 2004).

A recent study of motivation concluded that a positive predictor of academic success was the motivation to go to college to University students Coast EEST (Jessica et al., 2005).

Motivation is positively associated with academic performance among medical students of the University Medical Centre, Amsterdam, Netherlands (Kusurkar et al., 2011), (Shah 2010).

Our hypothesis is:

HO: There is a connection between the motivition and study branch.

\section{Methodology}

Number of subjects in our champion is 505. Of these, 88 are men and 417 are women. Although their involvement was random, there are used as criteria for the subjects to be in branches of Psychology, Social Work, Economics, History and Psycho-sociology. Also they must be students of the second year.

Tirana university - 214 students; "Alexander Moisiu" of Durres- 109 students; University "Luigj Guraguqi" of Shkodra - 182 students

Students Motivation Questionnaire 2nd version (TUSMQ-2) its used as a tool to collect relevant data about the motivation of students to attend university contains 30 claims (Item) distributed equally to every motivational.

There were two elements of internal motivation; Self-exploration and Altruism and four external motivations: refusal of alternative options, career and qualifications, social satisfaction, and social pressure on the questionnaire.

Each motivational contains five claims. They are based on the eight point Likert scale, for each statement, the students evaluated themselves on a scale from 1 to 8; 1 is "Very False", and ending in 8 "very real". Student academic achievement was measured using cumulative data, overall average grades (GPA).

Data were coded and analyzed using SPSS program, version 16. Basic descriptive statistical analyzes were performed to determine the frequency distributions, M, SD study variables. Pearson correlation coefficients were calculated to assess the relationship between the variables of the study. 


\section{Results}

Descriptive Statistics

\begin{tabular}{|l|c|c|c|c|c|}
\hline & $\mathrm{N}$ & Minimum & Maximum & Mean & Std. Deviation \\
\hline Total motivation (TM) & 505 & 2.38 & 7.88 & 5.5649 & .80319 \\
Internal motivation (IM) & 505 & 2.20 & 8.00 & 6.1444 & 1.01084 \\
External motivation (EM) & 505 & 2.55 & 7.75 & 4.9854 & .89947 \\
Valid N (listwise) & 505 & & & & \\
\hline
\end{tabular}

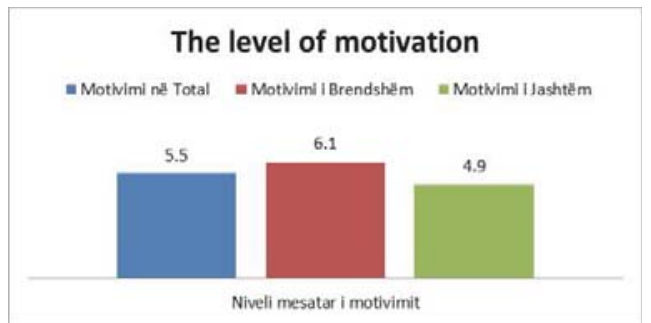

As in the graphic its appair the mean of total motivation (TM) is 5.5649, the mean of internal motivation (IM) is 6.1444 and the mean of external motivation (EM) is 4.9854 .

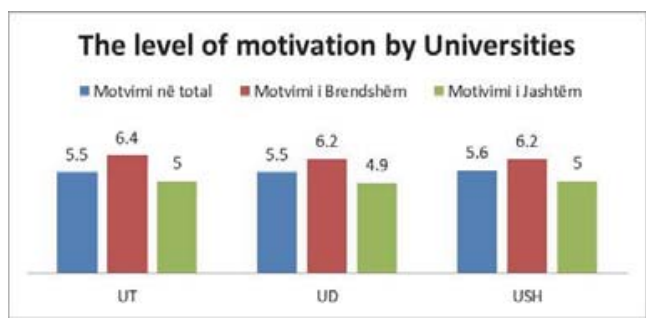

The level of motivation by universities is:

\begin{tabular}{|l|c|c|c|}
\hline Level of motivation & University of Tirana (UT) & University of Durres (UD) & University of Shkoder (USH) \\
\hline Total of motivation TM & 5.5 & 5.5 & 5.6 \\
\hline Internal motivation IM & 6.4 & 6.2 & 6.2 \\
\hline External motivation EM & 5 & 4.9 & 5 \\
\hline
\end{tabular}

The value of internal motivation are higher that the value of external motivation, but the differences its statisticly not significant.

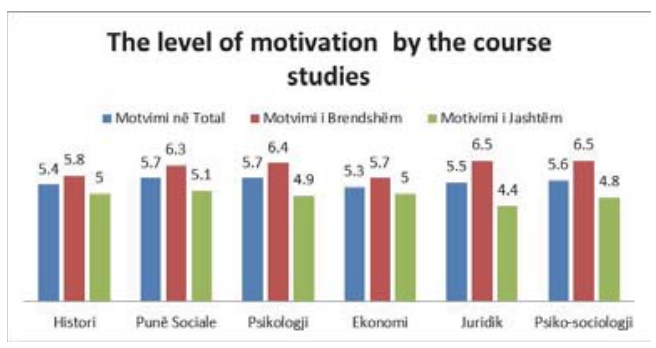

The above graph shows the values of the level of student motivation by their branch of study. In History branch the values are 5.4 for TM, 5.8 for IM and 5 for EM. In Social Work the values are 5.7 for TM, 6.3 for IM and 5.1 for EM. In Psychology the values are 5.7 for TM, 6.3 for IM and 4.9 for EM. The students of The Economy have these value 5.3 for 
TM, 5.7 for IM and 5 for EM. For the students of Justice the values are 5.5 for TM, 6.5 for IM and 4.4 for EM. Even here the internal motivation values are higher than those external motivation, although this difference was not significant. The most value is 6.5 appairs in the branch of Justice and Psycho-Sociology.

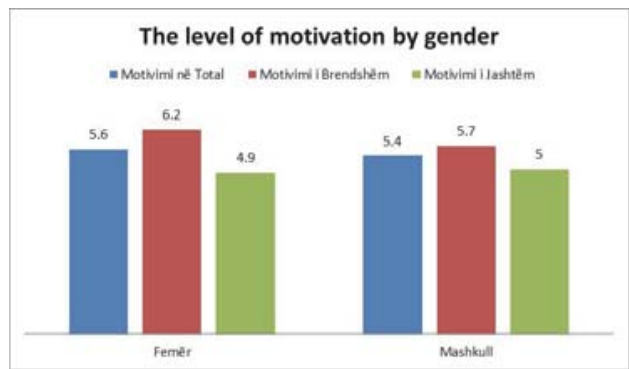

The female students have the value 5.6 for TM, 6.2 for IM and 4.9. The value for the male students are 5.4 for TM, 5.7 for IM and 5 for EM. students.

Higher values by gender we find to Internal Motivation (IM) namely 6.2 for females students and 5.7 for males

\section{Discussions}

Recording the table of Descriptive statistics, we can tell that our students show satisfactory levels of motivation. This consideration applies to the external motivation that internal as well. The values presented in the table below show that students tend to our sample towards external motivation both internal him. Also, if we refer the values according to the branches study we can say that the values of motivation are not dictated by the branch of study. Although there is an important distinction we can not say that female students have higher values of motivation, especially internal motivation.

\begin{tabular}{|c|c|c|c|c|c|c|}
\hline \multicolumn{7}{|c|}{ Descriptive Statistics ${ }^{a}$} \\
\hline & $\mathrm{GA}$ & $\mathrm{N}$ & Minimum & Maximum & Mean & Std. Deviation \\
\hline \multirow{3}{*}{ History } & MT & 105 & 2.95 & 7.40 & 5.4278 & .87552 \\
\hline & IM & 105 & 2.90 & 7.67 & 5.8758 & 1.03253 \\
\hline & EM & 105 & 2.60 & 7.40 & 4.9798 & 1.01835 \\
\hline \multirow{5}{*}{ Social Work } & Valid N (listwise) & 105 & & & & \\
\hline & TM & 83 & 3.63 & 7.28 & 5.7438 & .74854 \\
\hline & IM & 83 & 3.90 & 7.89 & 6.3080 & .86437 \\
\hline & EM & 83 & 2.95 & 7.15 & 5.1796 & .90565 \\
\hline & Valid N (listwise) & 83 & & & & \\
\hline \multirow{4}{*}{ Psychology } & TM & 143 & 3.55 & 7.08 & 5.7067 & .73377 \\
\hline & IM & 143 & 3.00 & 8.00 & 6.4855 & .92106 \\
\hline & EM & 143 & 2.75 & 7.10 & 4.9279 & .83200 \\
\hline & Valid N (listwise) & 143 & & & & \\
\hline \multirow{4}{*}{ Economics } & TMotivimi ne Total & 128 & 2.38 & 7.88 & 5.3760 & .82942 \\
\hline & IM & 128 & 2.20 & 8.00 & 5.7364 & 1.04359 \\
\hline & EM & 128 & 2.55 & 7.75 & 5.0157 & .84558 \\
\hline & Valid N (listwise) & 128 & & & & \\
\hline \multirow{4}{*}{ Justice } & TM & 11 & 4.40 & 6.32 & 5.4995 & .51439 \\
\hline & IM & 11 & 5.50 & 7.80 & 6.5636 & .72701 \\
\hline & EM & 11 & 3.30 & 5.15 & 4.4354 & .66635 \\
\hline & Valid N (listwise) & 11 & & & & \\
\hline \multirow{4}{*}{ Psyco-sociology } & TM & 35 & 3.55 & 7.11 & 5.6838 & .77446 \\
\hline & EM & 35 & 4.20 & 7.60 & 6.5286 & .83897 \\
\hline & IM & 35 & 2.90 & 6.72 & 4.8391 & .95954 \\
\hline & Valid N (listwise) & 35 & & & & \\
\hline
\end{tabular}




\section{Conclusions}

Regarding types of motivation to attend university, students reported high levels of both motivations.

There are differences between branches of study and by sex than students, but these differences are statistically insufficient. This means that our hypothesis was not confirmed.

Regarding external and internal motivation, careers and qualifications were the most common motivators external to the students attending university, followed by internal motivating altruism, and self-exploration, and social satisfaction, the refusal of alternative options, and social pressures are reported as external motivator to attend university.

\section{References}

Sahar Mahmoud Radi. Baccalaureate Nursing Students' Motivation for Attending University and its Relationship with their Academic Achievement. International Journal of Education and Research Vol. 1 No. 7 July 2013

Hasan Afzal; Imran Ali; Muhammad Aslam Khan; Kashif Hamid. A Study of University Students' Motivation and Its Relationship with Their Academic Performance. International Journal of Business and Management

Pei-Ling Lee and Vincent Pang. Motivational orientations in adult learning: comparing a public and private university. Journal of Institutional Research in South East Asia - Vol. 11 No. 2 Oct/Nov 2013. P. 6.

Pei-Ling Lee \& Vincent Pang. The influence of motivational orientations on academic achievement among working adults in contiuing education. International Journal of Training Research. Vol 12. Issue 1. (2014). http://jtr.e-contentmanagement.com/archives /vol/12/issue/1/

Pei Ling Lee \& Vincent Pang. Motivational Factors in Continuing Education and Academic. Malaysian Journal of Learning \& Instruction. http://mjli.uum.edu.my/index.php/current-issues/viewdownload/16-mjli-vol-10-2013/76-motivational-factors-in-continuingeducation-and-academic-achievement-of-adult-learners

Najmus Saher Shah. Predicting factors that affect students'academic performance by using data mining techniques. Pakistan business review January 2012. P. 631. Appendix 5: Similar Questions used in survey of study by Afzal, H.,Imran,A., Khan,M.A. and Kashif,H. (2010). P. 666. 